\title{
The Histological Structure of the Upper and Lower Jaw Teeth in the Gobiid Fish, Sicyopterus japonicus
}

\author{
by
}

\begin{abstract}
Yoshiko KAKIZAWA, Noboru KAJIYAMA, Ken NAGAI, Kunihito KADO, Masaki FUJITA, Yoshio KASHIWAYA, Chikako IMAI, Akihiro HIRAMA and Masaya YORIOKA
\end{abstract}

(Received 4 June 1986)

Key words: Sicyopterus japonicus, upper- and lower-jaw teeth, tricuspid tooth, hinged structure, feeding habits

\section{Summary}

The histological structure of upper- and lower-jaw teeth of Sicyopterus japonicus, a fish known to exhibit rock-climbing behavior, were examined by light microscopy and scanning electron microscopy.

The upper jaw teeth and the lower jaw teeth were entirely different in form. The characteristics of the upper jaw teeth were that the enameloid constituting the tip of the tooth had a shovel-like shape and that there were many eruptive teeth behind each of which lay a large number of successional teeth ready for continuous replacement. The shape of the enameloid was suited to the work of scraping algae from the surface of stones. The lower jaw teeth had a hinged structure.

It was suggested that the forms of teeth in Sicyopterus japonicus were the result of the fish's adaptation to its feeding habit, rather than its rock-climbing nature.

\section{Introduction}

Sicyopterus japonicus TANAKA is a fish belonging to the family Gobiidae that lives in and to the west of the Kanto District, along the coastal regions facing the Pacific Ocean and southwards to the northern region of Taiwan. The fish spawns in and around the midstreams of rivers in July and August each year. The young hatchling fish travel down the rivers into the sea, where they spend a period of about eight months floating and swimming before beginning their journey back up the rivers in around March-May of the following year.

Sicyopterus japonicus is known for the strange behavior it exhibits while travelling upstream. When the fish meets a downstream torrent, it avoids the stream, heads for the foot of a vertical rock-wall or an overhanging rock where there is no water coming down, and climbs up the rock.

With regard to this rock-climbing behavior of the fish, FUKUI ${ }^{[1]}$ has reported that the fish may perhaps be using its pelvic disc, fleshly tubercle and teeth.

*柿澤佳子, 梶山 愓, 永井 謙, 角 邦人, 藤田正樹, 柏谷良雄, 今井千香子, 平間章弘, 依岡正也： Department of Anatomy, Nihon University School of Dentistry. 
It has also been reported by DotU et al. ${ }^{[2]}$ that the fish undergoes a change in feeding habit when it moves its habitation from the sea to the midstream of a river. After living on a diet of phyto- and zooplankton in the marine stage of its life cycle, it begins to feed herbivorously on items such as diatoms and blue-green algae that grow on the surface of stones once it reenters a river and reaches midstream.

In the present study, in order to find out if the teeth of Sicyopterus japonicus are of a form suited to this change in feeding habit and the fish's rock-climbing behavior, the authors observed the process of development of the upper and lower jaw teeth and their histological structure. The following is a report on the findings made as a result of these observations.

\section{Materials and Methods}

The locations from which the authors obtained specimens of the fish from which to produce tissue sections were as follows:

1) Two juveniles, each about $2.8 \mathrm{~cm}$ long

-The Chinase River, Naze City, Kagoshima Prefecture

(Caught on July 6, 1972)

2) Two juveniles, each about $3.4 \mathrm{~cm}$ long

-The Akina River, Setouchi-cho, Oshima District, Kagoshima Prefecture

(Caught on July 11, 1972)

The specimens from locations 1) and 2) above were made available by courtesy of Mr. Katsusuke Meguro of the Crown Prince's Palace.

3) Ten adults, each about $10 \mathrm{~cm}$ long

- The Takada River (a branch of the Kumano River), Shinguu City, Wakayama Prefecture

(Caught on August, 31, 1977)

Specimens from location 3) above were made available by courtesy of $\mathrm{Mr}$.

Shojiro Fukui of Nachi-Katsuura, Wakayama Prefecture.

Each fish, which had been fixed in $10 \%$ formalin at the location where it was caught, was cut into various pieces, such as the head and the mouth region, which were again fixed in $10 \%$ formalin.

After being washed with water, the juveniles about $2.8 \mathrm{~cm}$ long and about $3.4 \mathrm{~cm}$ long and also the adults were embedded in paraffin and celloidin after dehydration, in accordance with the usual method. Prior to this process, the adults were decalcified with $5 \%$ trichloroacetic acid.

Sagittal, horizontal and frontal sections, each of about $10-15 \mu \mathrm{m}$ in thickness, were cut, stained with hematoxylin \& eosin, azan and Masson-Goldner (M-G) stains, and observed by light microscopy.

The upper and lower jaw teeth of the 3.4-cm-long juveniles were fixed in $10 \%$ formalin. They were then dehydrated and critical-point dried, sputter-coated and observed by scanning electron microscopy.

\section{Results}

1. Exterior form of the upper and lower jaw teeth

The upper-jaw teeth and the lower-jaw teeth of Sicyopterus japonicus were 
entirely different in form (Fig. 1). The upper-jaw teeth, all small, were located underneath the thick upper lip, where each of the eruptive teeth was arranged in front of a row of successional teeth, each undergoing continuous replacement. The lowerjaw teeth, on the other hand, were all large ones.

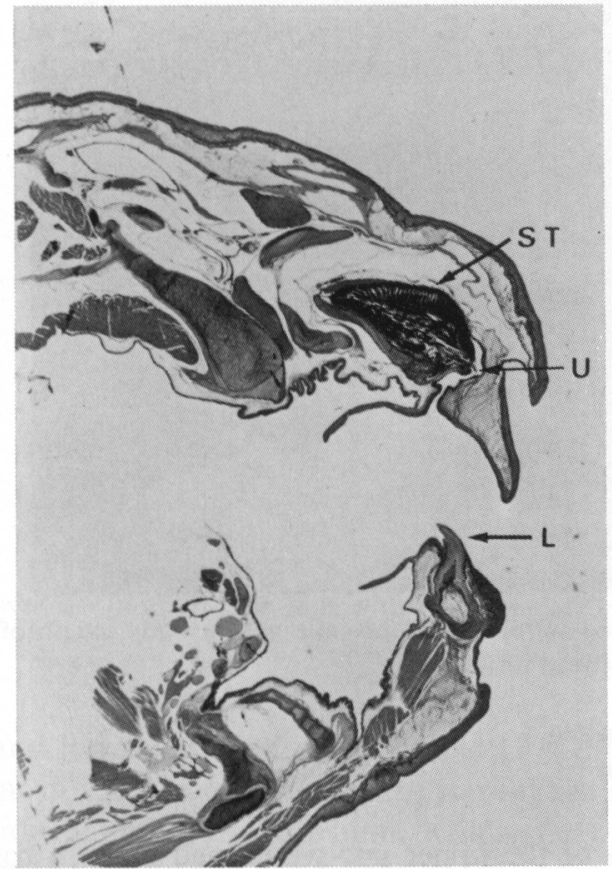

Fig. 1 The upper and lower jaw teeth of Sicyopterus japonicus (adult, decalcified sagittal section, H-E stain)

ST: successional teeth

$\mathrm{U}$ : upper tooth

L: lower tooth

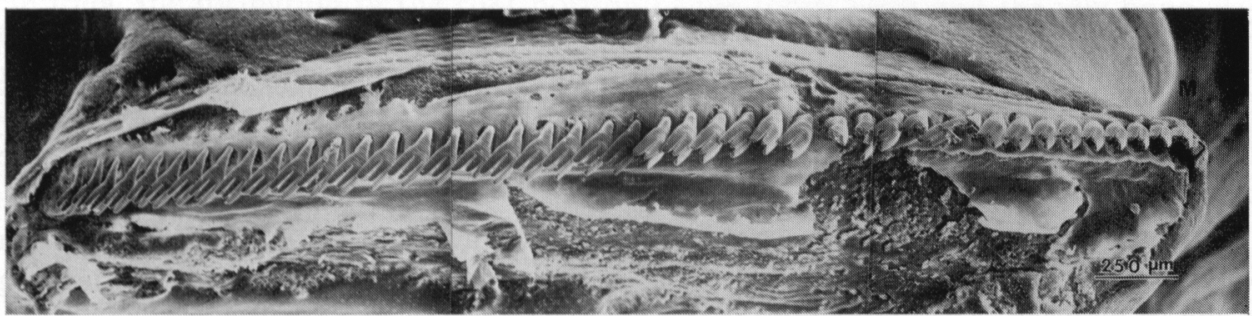

Fig. 2 The eruptive teeth of the upper jaw which are lined up in a row on the outside of a semicylindrical-shaped sac.

M: mesial

(SEM)

D: distal 


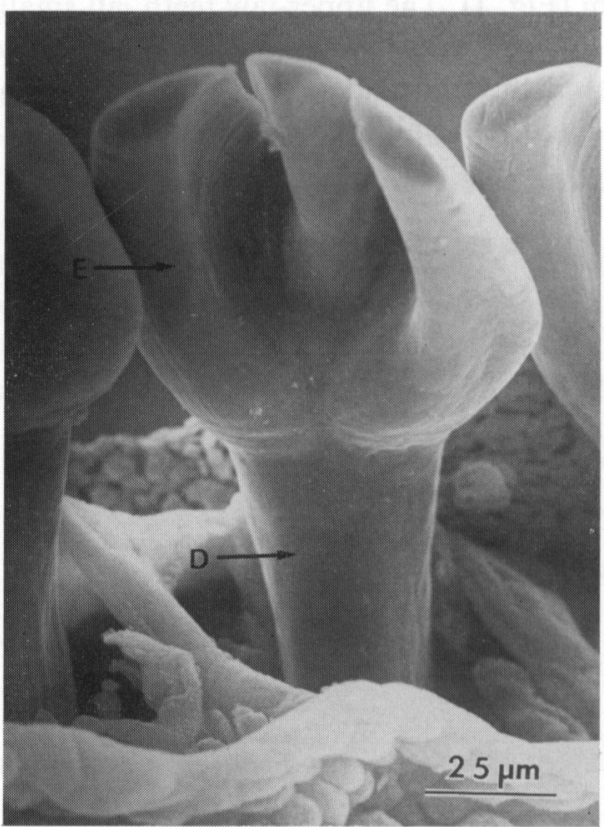

Fig. 3 An upper-jaw tooth of a juvenile with a body length of about $3.4 \mathrm{~cm}$, observed!from inside.

E: enameloid

(SEM)

D: dentin

The eruptive teeth of the upper jaw were lined up in a row, the shovel-shaped enameloid consisting of yellowish-brown tricuspid with part of the dentin protruding on the outside of a semicylindrical-shaped sac (Fig. 2).

The enameloid, which constitutes the tip of the upper-jaw tooth, was divided into three; the central section had a slightly narrow width, while the outer two sections were both about equally wide. All of the tips were worn. When observed from inside, the enameloid resembled a human palm and it was clearly possible to see that it had a shovel-like form suited to the work of scraping small species such as diatoms and cyanophytes from the surface of stones (Fig. 3:E). The lower layer of the enameloid was seen to consist of dentin (Fig. 3:D) which, when protruding into the oral cavity, was considerably inclined toward the interior of the cavity.

The eruptive tooth of the lower jaw had a structure with a swollen tip which was in contact with the epithelium of the upper edge of the lower-jaw bone, leaving a gap in between. The epithelium of the bordering region was swollen (Fig. 4).

2. Development of tooth germ and the histological structure of teeth

1) Juveniles about $2.8 \mathrm{~cm}$ long

In the case of juveniles with a length of about $2.8 \mathrm{~cm}$ which had just started to swim upriver after completing their marine floating and swimming period ${ }^{[2]}$, 


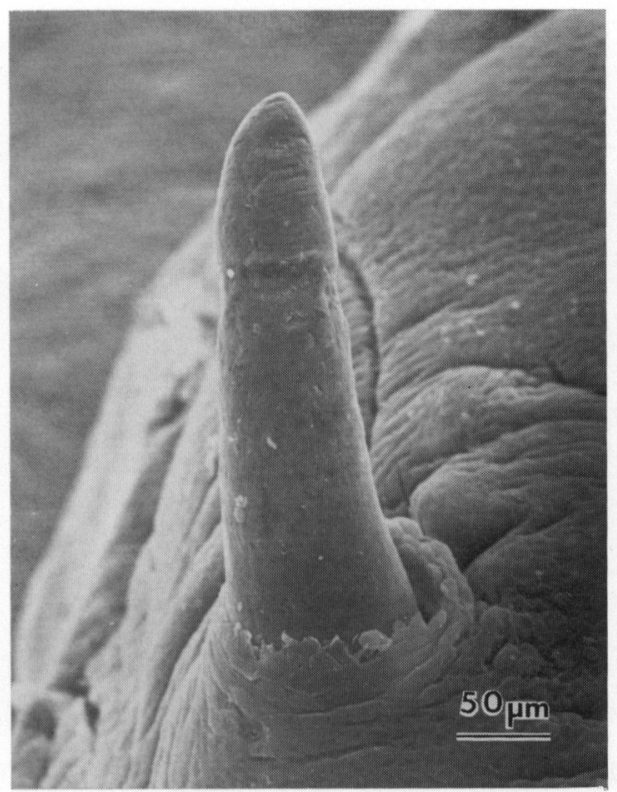

Fig. 4 A lower-jaw tooth of a juvenile with a body length of about $3.4 \mathrm{~cm}$

(SEM)

none of the upper- and lower-jaw teeth had erupted (Fig. 5). As for the upper-jaw teeth, the development of tooth germ was seen to start at the tip of the dental lamina formed by invagination of the oral epithelium, with greater development progressing in the direction of the arrow and the height of the tooth germ becoming greater toward that direction (Fig. 5). After the matrix of the enameloid had been formed, the dentin began to develop and then a high degree of calcification of the enameloid was observed. It made a U-turn at the left end, advanced toward the labial side and became an eruptive tooth after becoming attached to the jaw bone and forming a connection with a fibrous structure. However, in the case of juveniles about 2.8 $\mathrm{cm}$ long, the formation of the root portion of the tooth germ and the jaw bone was inadequate and so the attachment could not be observed (Fig. 5). At the tips of germ teeth which had almost become complete teeth, yellowish-brown highlycalcified enameloid was visible (Fig. $5: \mathrm{E}$ ). By the time the fish had grown to about $2.8 \mathrm{~cm}$ in length, the successional teeth of the upper jaw had formed up to a maximum of 13 generations.

As for the germ teeth of the lower jaw, tooth development was seen to start at the tip of the dental lamina which was formed by invagination of the oral epithelium (Fig. 6).

2) Juveniles about $3.4 \mathrm{~cm}$ long

By the time fish begin to swim upriver in schools and reach the midstream of the river, their total body length will have grown to about $3.4 \mathrm{~cm}^{[2]}$. When such a stage is reached, the teeth at the tip of the upper jaw become united with the jaw 


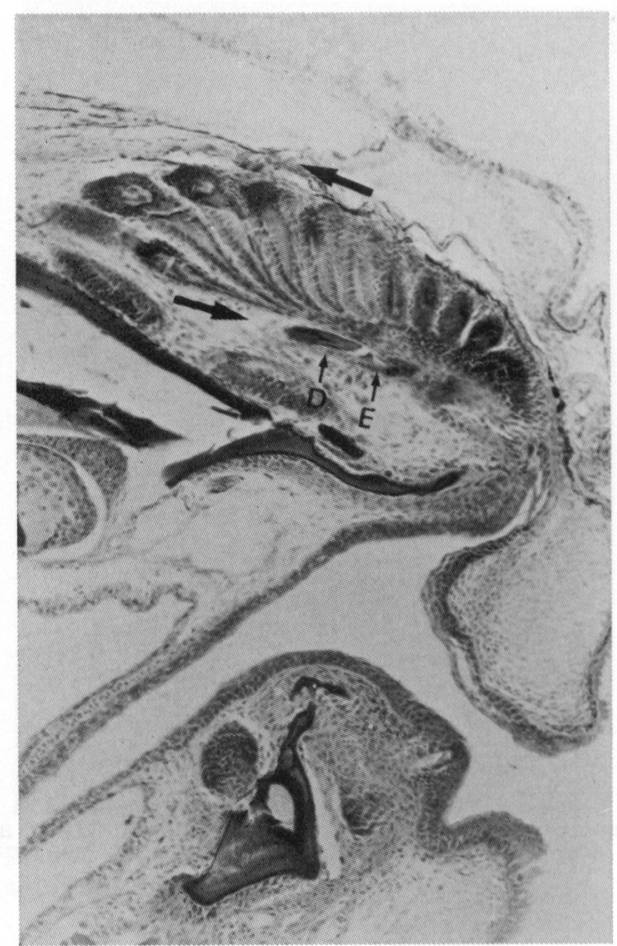

Fig. 5 The upper- and lower-jaw teeth of a juvenile with a body length of about $2.8 \mathrm{~cm}$

D: dentin

(sagittal section, H-E stain)

E: enameloid

bone and erupt (Fig. 7), as in the case of the lower-jaw teeth, one each at the left and the right (Fig. 8). The successional teeth of the upper jaw were seen to have formed up to a maximum of 30 generations. At around the stage where the enameloid makes a U-turn at the left end, it was observed that the exterior form of the enameloid had been completed and that calcification had begun (the arrow in Fig. 7). The enameloid had the appearance of three petal-like bodies facing toward the center, each of the three bodies being sharp in the middle and blunted on both sides, and with a pointed tip. It appeared to be a very special form, entirely different from that of dentin (Fig. 9). The link with the dentin was not firm; the enameloid came off easily when sections were made.

3) Adults about $10 \mathrm{~cm}$ long

In the case of an adult ${ }^{[2]}$ with a body length of about $10 \mathrm{~cm}$, the successional teeth of the upper jaw are already formed up to a maximum of 45 generations.

The dentin of each upper-jaw tooth (Fig. 10) was observed to have a thin cylindrical shape which was slightly swollen at the portion near the base (Fig. 11) and had an orthodentin-like appearance. Those odontoblasts in the upper part 


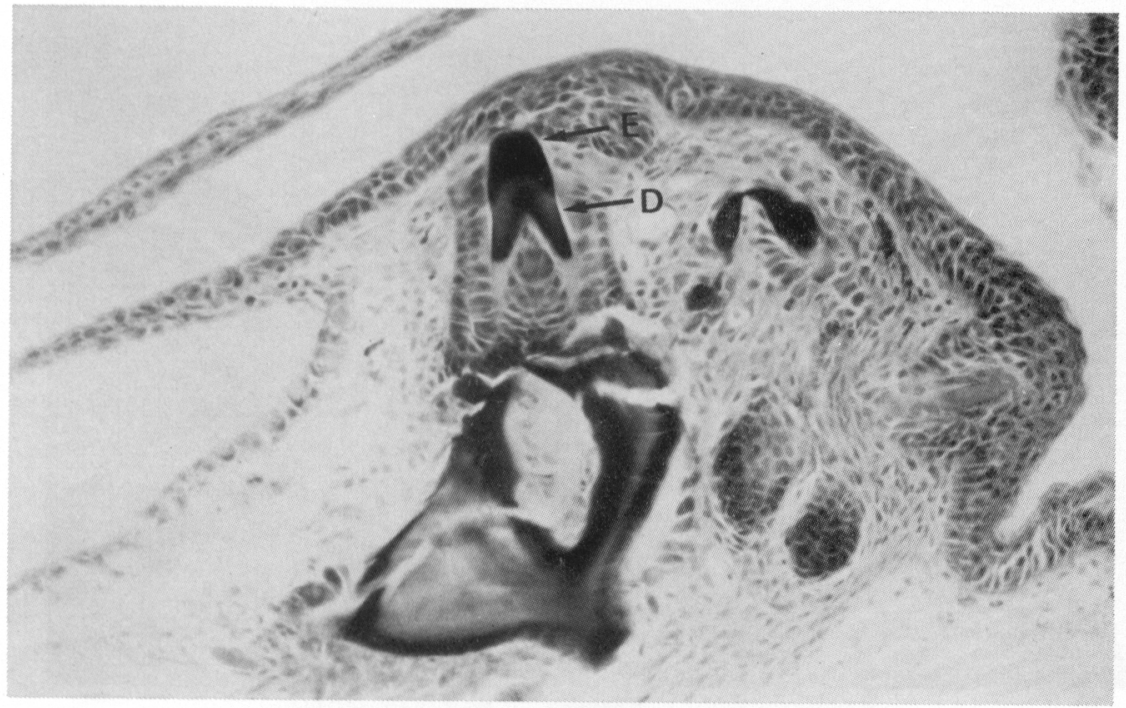

Fig. 6 A lower-jaw tooth of a juvenile with a body length of about $2.8 \mathrm{~cm}$

E: enameloid

(sagittal section, H-E stain)

D: dentin

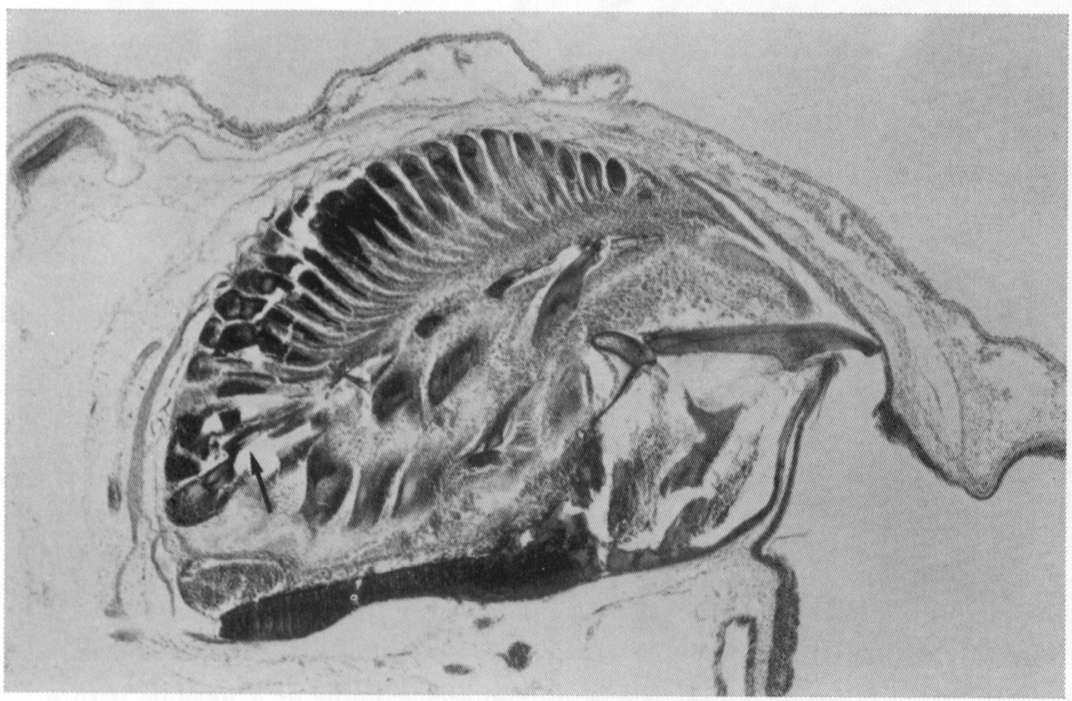

Fig. 7 The upper-jaw teeth of a juvenile with a body length of about $3.4 \mathrm{~cm}$ arrow: calcified enameloid (sagittal section, H-E stain) 


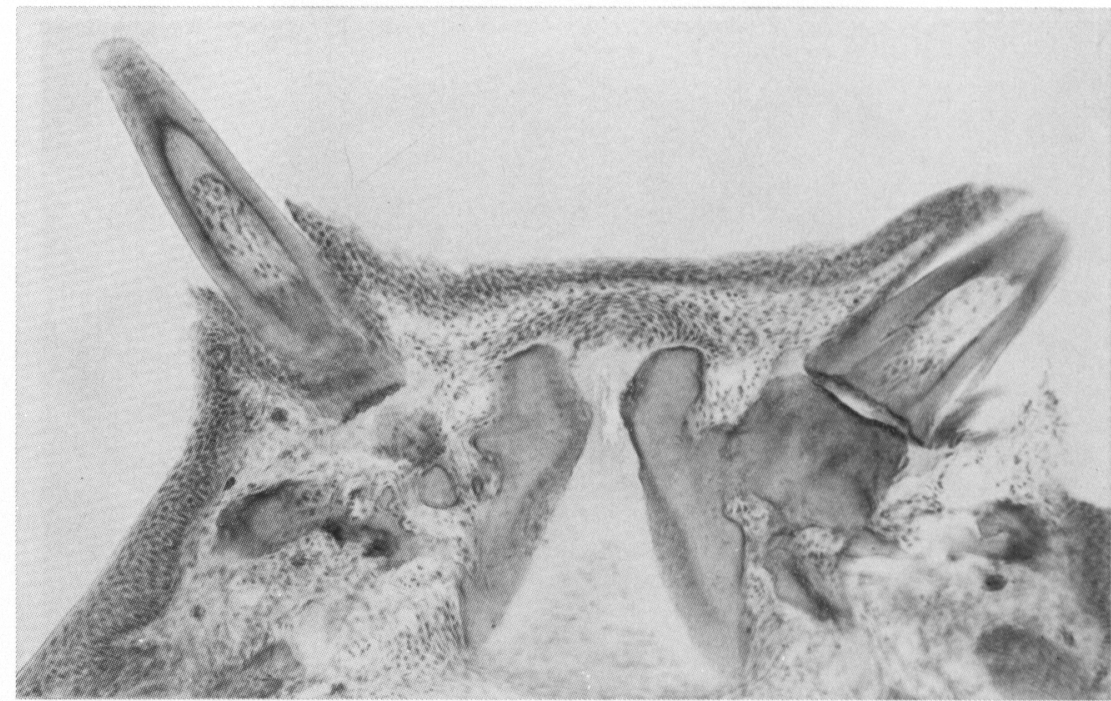

Fig. 8 The lower-jaw teeth of a juvenile with a body length of about $3.4 \mathrm{~cm}$

(sagittal section, H-E stain)

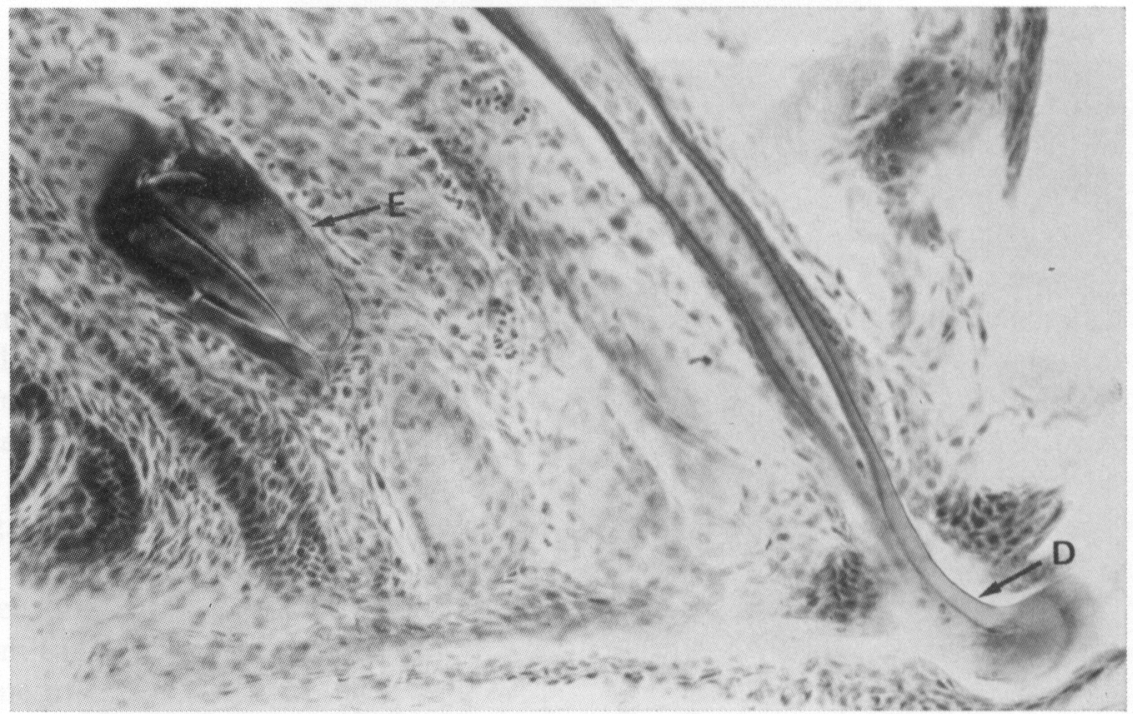

Fig. 9 The enameloid of an uneruptive upper-jaw tooth of a juvenile with a body length of about $3.4 \mathrm{~cm}$

E: enameloid

(frontal section, H-E stain)

D: dentin 


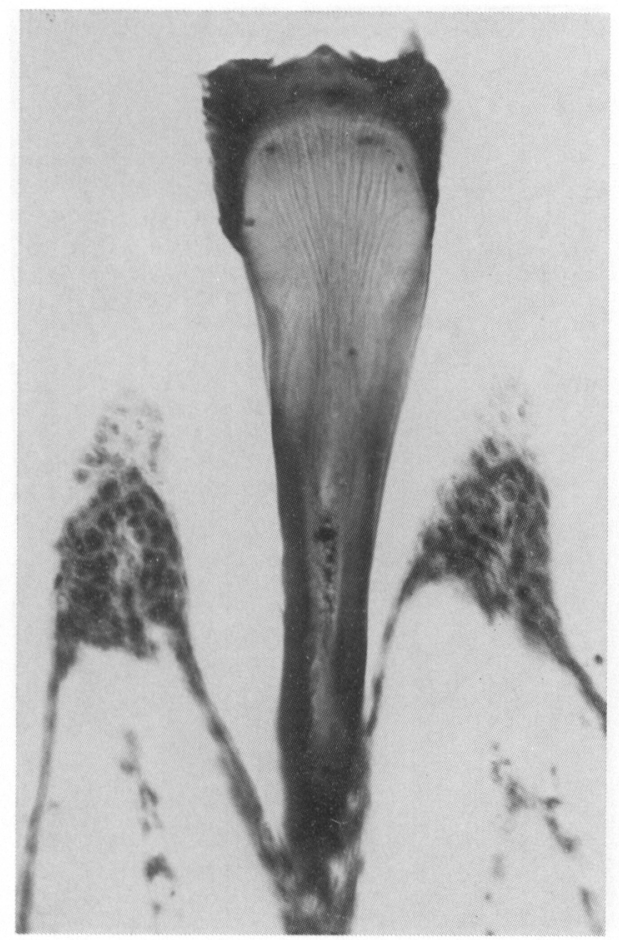

Fig. 10 The dentin of an eruptive upper-jaw tooth of an adult. The enameloid has been removed by decalcification.

(decalcified horizontal section, H-E stain)

were sparse and low in height, those in the central part were high (Fig. 11:HO) and those in the basal part were densely packed (Fig. 11:DO).

The lower-jaw tooth had a canine-like appearance and consisted mainly of dentin. The odontoblasts were extremely densely packed (Fig. 12). The portion at the tip which was stained differently from dentin was enameloid (Fig 12:E). The lower-jaw teeth had a hinged structure (Fig. 13:F) and were inclined toward the interior of the oral cavity. There was not such a large number of successional teeth as were seen in the case of the upper jaw.

\section{Discussion}

The development of both the upper- and lower-jaw teeth of Sicyopterus japonicus was observed to begin at the tip of the dental lamina which was formed by invagination of the oral epithelium. Each tooth had a unique structure which was considered to be closely related to its function.

The main characteristics of the upper-jaw teeth were that the enameloid constituting their tips had a unique shovel-like form, and that there were many eruptive teeth, behind each of which there was a 1 arge number of successional teeth for continuous replacement, enclosed within a sac. 


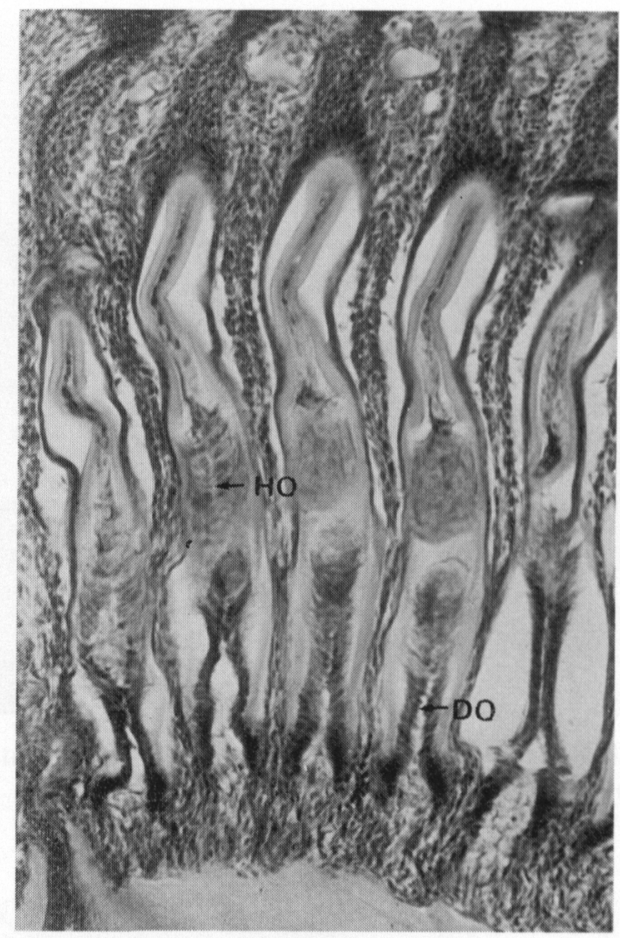

Fig. 11 The dentin of an uneruptive upper-jaw tooth of an adult (decalcified horizontal section, H-E stain) HO: higher odontoblast DO: dense odontoblast

The enameloid is known to take various forms according to feeding habit. SHELLIS ${ }^{[3]}$ stated that the type of enameloid which is confined to the tip of a tooth and has a cap-like appearance is characteristic of an animal that has a "scraping off" type of feeding habit. The enameloid of mugilid fish is of a cap form similar to that of Sicyopterus japonicus, the tip being bicuspid and yellow. It has been reported that mugilid fish eat algae growing mainly on stones by scraping them off ${ }^{[4]}$. As for the enameloid of the upper-jaw teeth of Sicyopterus japonicus, the shovel-shaped tricuspid was observed to be perched on the tip of the dentin and, moreover, a large number of teeth, each with a form the same as that described above, were lined up in a single row. We consider this structure to be well suited to the feeding habit of a fish which scrapes algae from stones with its teeth. Behind each eruptive tooth were observed several generations of successional teeth for continuous replacement. This large number of successional teeth can be considered to be the fish's adaptation to the considerable attritional damage occurring as a result of scraping algae from stones. The tip of the enameloid immediately before tooth eruption was pointed (Fig. 9), whereas the tips of the erupted teeth were invariably worn (Fig. 3). This was probably due to the contact made with the teeth when the fish scrapes the algae 


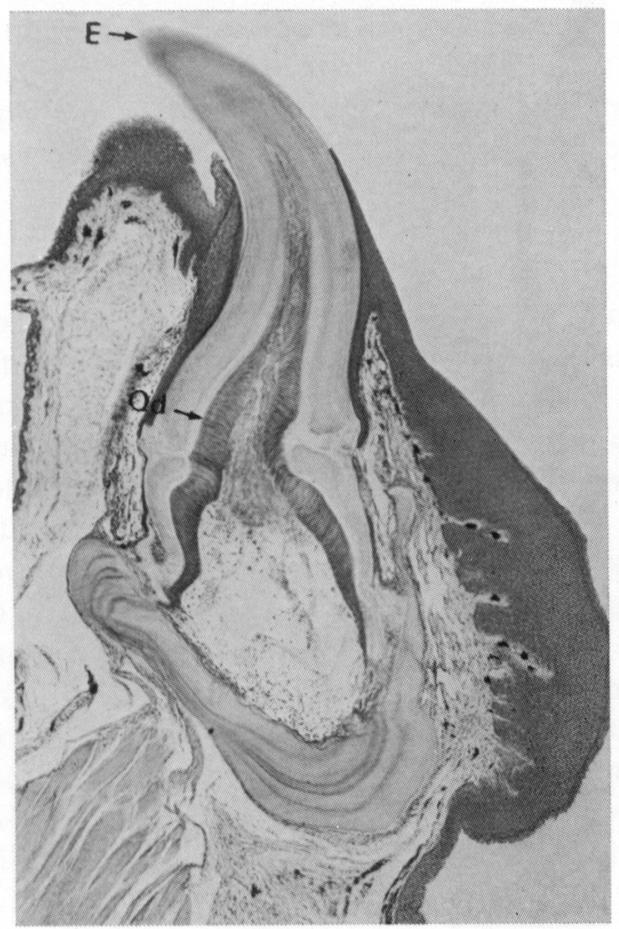

Fig. 12 A lower-jaw tooth of an adult (decalcified sagittal section, H-E stain)

E: enameloid

Od: odontoblast

from the surface of stones. The arrangement of the successional teeth was such that each tooth first grew into the interior of the oral cavity, before making a Uturn and heading back toward the labial side to become an eruptive tooth. This bent structure may be considered suitable for a large number of successional teeth to be made ready within a restricted structure in which the entire set of the upperjaw teeth is enclosed within a sac.

One of the morphological characteristics of the lower-jaw teeth was that they had a hinged structure. This type of structure was confirmed from SEM observations (Fig. 4) as well as from the findings that each lower-jaw tooth moved when touched with the tip of a pair of tweezers and that a fibrous structure was revealed upon hematoxylin and eosin staining and azan staining of the sections (Fig. 13). According to KUвотA ${ }^{[5]}$, the hinged structure prevents failure in catching food. In the case of the lower-jaw teeth of Sicyopterus japonicus, also, in view of the appearance of teeth that were inclined toward the inside of the oral cavity and also of the presence of the hinged structure of the interior, it can be considered that the lower-jaw teeth may play a role of delivering into the mouth algae which have been scraped from stones with the upper-jaw teeth. 


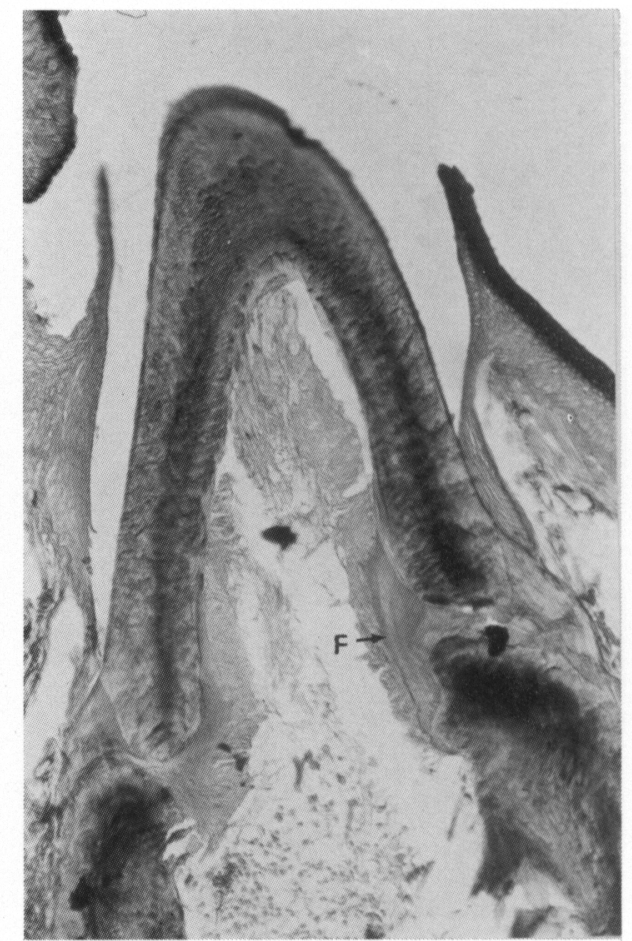

Fig. 13 The hinged structure of a lower-jaw tooth of an adult (sagittal section, azan stain) F: collagen fibers

From the above, it is suggested that the characteristics of tooth-form in Sicyopterus japonicus are the result of the fish's adaptation to its feeding habit, rather than the result of its rock-climbing nature. The observation that the form and growth of the mouth region are closely related to changes in feeding habit has been reported by KomADa ${ }^{[6]}$ in his studies of the teeth of pond smelt. Also, in the case of Sicyopterus japonicus, its teeth, as MochIZUKI ${ }^{[7]}$ has stated, must have been formed as a result of their adaptation to the changes in feeding habit shown by the fish which, after leaving the sea, returns to a freshwater environment to feed on algae attached to stones. While the upper- and lower-jaw teeth of juveniles immediately after entering the river have not yet erupted, they begin erupting by becoming connected with the jaw bones when the fish start swimming upriver. From this, it can be considered that the upper- and lower-jaw teeth of Sicyopterus japonicus become prepared for use as soon as the fish enter the river and begin feeding on algae. In addition, the large number of successional teeth in the upper jaw indicates not only the adaptation of the fish to the attrition suffered by teeth at the time of scraping algae from stones but also to the damage the fish suffers when exhibiting behavior such as rock-climbing and jumping up onto rocks.

According to GosLINE ${ }^{[8]}$, the type of dentition is related to feeding habit; grasp- 
ing dentition is of ancestral type, while the development of scraping, biting, and shearing dentition continues over a period of many years. In view of the fact that Sicyopterus japonicus has upper-jaw teeth that are suitable for scraping and lowerjaw teeth that are completely different in form, a characteristic rarely seen in fishes ${ }^{[9]}$, the teeth of this species may be regarded as being fairly specialized forms of fish teeth.

\section{Conclusions}

Sections of the upper- and lower-jaw teeth of the adults and juveniles of Sicyopterus japonicus were made and observed by light microscopy and SEM. As a result, the following conclusions were obtained:

1. Both the upper- and lower-jaw teeth were induced by the dental lamina formed by invagination of the oral epithelium and the development was observed to start at the tip of the dental lamina.

2. The upper and lower jaw teeth had different characteristics in that the former consisted of many successional teeth arranged for continuous replacement, while the latter had a hinged structure.

3. The -enameloid of the upper-jaw tooth had the shape of a tricuspid shovel, suited to the work of scraping algae from the surface of stones.

4. Whereas the upper- and lower-jaw teeth of juveniles immediately after their entry into the river from the sea were unerupted in most cases, the teeth of fish over $3.4 \mathrm{~cm}$ in length which had just started swimming upriver in schools were all erupted. This suggested their adaptation to the changes taking place in their feeding habit.

5. The large number of successional teeth in the upper jaw seemed to suggest the fish's adaptation to the attrition suffered at the time of scraping algae from stones and also to the loss of its teeth at the time of jumping up onto rocks or climbing up rock walls.

\section{References}

[1] Fukui, S.: On the rock-climbing behavior of the goby, Sicyopterus japonicus, Japan. J. Ichthyol., 26 (1), 84-88, 1979 (in Japanese)

[2] Dotu, Y. and S. Mrto: Life history of a gobiid fish, Sicydium japonicus Tanaka, Sci. Bull. Fac. Agr., Kyushu Univ., 15 (2), 213-221, 1955 (in Japanese)

[3] Shellis, R.P.: The role of the inner dental epithelium in the formation of the teeth in fish. In: Development, Function and Evolution of Teeth, 31-42, Academic Press Inc. (London), 1978

[4] Ebeling, A. W.: The dentition of eastern pacific mullets, with special reference to adaptation and taxonomy, COPEIA, No. 3, 173-185, 1957

[5] Kuвота, K.: A study on the hinged structure of the teeth of fishes, Nihon Univ. dent. J., 44, 406-411, 1970 (in Japanese)

[6] Komada, N.: The mouth shape and the distribution of teeth of young and adult Hypomesus transpacificus nipponensis, Jap. J. Oral Biol. 22, 289-299, 1980

[7] Mochizuki, K.: Rock-climbing fish [Sicyopterus japonicus], ANIMA, 108, 29-33, 1982

[8] Gosline, W. A.: Consideration regarding the phylogeny of cypriniform fishes, with special reference to structures associated with feeding, COPEIA, 4, 761-777, 1973

[9] Kirino, T.: The tooth development (3) Phylogeny of tooth, Dental Outlook, 18, 1330-1344, 1961 (in Japanese) 